\title{
Modification or Adjustment
}

National Cancer Institute

\section{Source}

National Cancer Institute. Modification or Adjustment. NCI Thesaurus. Code C53606.

An indication that a change in treatment or a change to a device will be required following an adverse event. 